\title{
A Framework for Green Growth and Socio-Economic Development in Malaysia
}

\author{
NEGIN VAGHEFI*, CHAMHURI SIWAR and SARAH AZIZ ABDUL GHANI AZIZ
}

Institute for Environment and Development (LESTARI), Universiti Kebangsaan Malaysia, 43600 UKM Bangi, Selangor Darul Ehsan, Malaysia.

http://dx.doi.org/10.12944/CWE.10.1.04

(Received: November 30, 2014; Accepted: January 27, 2015)

\begin{abstract}
The green growth or green economy concept presents opportunities for more inclusive growth while protecting the environment. Malaysia has experienced rapid economic growth with gross domestic product annual growth rate averaged $4.1 \%$ over the period of 2004-2013. However, the rapid economic development may lead to declining focus on social equality. In Malaysia, although poverty has been reduced in trend, it is still a challenging issue, especially in rural areas. Greening the economy could integrate the social equality, as a pillar of sustainable development, with economic and environmental priorities. Indeed, it may improve the human well-being while significantly reducing environmental scarcity. A green economy could help to indicate the value of natural capital as a provider of human well being and a source of new jobs. This paper attempts to discuss on how green economy could improve the livelihood security and poverty eradication in Malaysia. It also seeks to understand what a socially transition to a green economy may look like and key interventions needed to achieve it.
\end{abstract}

Key words: Sustainable development, Green economy, Poverty, Social equality

\section{INTRODUCTION}

The common indicator of economic progress is growth in gross domestic product (GDP) which is computed as a sum of all final goods and services that produced within a period of time at market prices. Hence, a country could increase its GDP by depleting its natural capital. However, this growth would not be sustainable.

In recent years, Malaysia has experienced rapid economic growth which key drivers of such growth are private consumption and investment, especially in the services sector. However, this economic growth has been accompanied by environmental degradation. Malaysia is heavily dependent on the petroleum and timber industry which has significantly eroded its ability to remain economically sustainable. Degradation of natural resources generates a poverty trap, which causes a reinforcing loop of further degradation and worsening poverty. Thus, there is a circular link between poverty and environmental degradation (Figure 1). Since the poor communities are more reliant on natural resources, poverty may impact on environmental degradation. On the other hand, inequality and poverty may accelerate population growth and it may in turn impact on natural resources in terms of carrying capacity. It means natural resources would be overused to attain food security for households and it would result in environmental degradation. This degraded environment could in turn accelerate poverty incidence. Malaysia, as a developing country that the livelihood of its poor population is still highly dependent on natural resources and ecosystem services, should be very attentive about this issue. In fact, sustainable development plays a key role in helping to break the link between poverty and environmental degradation. 
Green economy is one of the important instruments to achieve sustainable development. United Nations Environment Programme (UNEP) defined green economy as "one that results in improved human well-being and social equity, while significantly reducing environmental risks and ecological scarcities." To achieve that type of economy, growth in income and employment should come from public and private investments which are low emitting, efficient in use of resources, and able to conserve biodiversity and environmental services. Malaysia therefore needs transformation to the green economy model that is more socially equitable and environmentally reasonable. This transition is necessary to reduce poverty and enable the development of the livelihood of the people who depends preliminary on natural resources. For Malaysian economy that is heavily dependent on natural resources, green growth would allow an efficient use of natural capital through efficient investment. Thus, Malaysia, for a successful transition to green economy, may need capacity building in technologies, financing and suitable policies.

\section{Impact of green economy on poverty}

In Malaysia, although poverty has been reduced in trend, it is still a challenging issue, especially in rural areas. In fact, rural communities benefit less from economic process than urban communities ${ }^{1}$. The misallocation of capital into economic sectors could be one of the important causes of poverty. This misallocation may lead to accelerate depletion of natural resources and ecosystems which the poor rural communities depend on them for their livelihood, nutrition, employment, income and wealth creation opportunities. Natural capital is necessary for sustainable economic development and any reduction in natural capital stocks and ecosystem services flow may result in growing inequality ${ }^{2}$. Malaysia's capital stock reflects the wealth of the country and wealth growth is mainly driven by natural capital. From an asset perspective, $19 \%$ of Malaysian's wealth is in natural capital, mainly oil and gas. Figure 2 shows the share of natural capital in the total wealth of the country.

For an efficient impact of green economy on poverty, relevant actions should be taken in various sectors that are targeting the less endowed. In the context of food security, attention will be paid to the development of the agricultural sector which plays an important role in economic growth and national income of the country. Promoting green economy activities around this sector would remarkably alleviate poverty and ensure food security and wellbeing in rural areas. Green agriculture or sustainable agricultural technique is one of the green economy activities in this sector. Greening the agriculture may increase food availability and alleviate poverty through building natural capital stock. An example of sustainable agriculture technique in Malaysia is System of Rice Intensification (SRI) as a methodology innovation used in sustainability for social development. SRI helps to conserve the local ecosystem and biodiversity, especially in water conservation. Since rice is a staple food in Malaysia, applying $\mathrm{SRI}$ is equally efficient to deal with the needs of rice security. This technique promotes the base for equity by benefiting small farmers. Promoting the sustainable practices would result in receiving a premium price for products, therefore helping to reduce poverty ${ }^{1}$.

In the context of increasing access to energy services which are still a problem for most remote and inaccessible parts of Malaysia, mostly in Sabah and Sarawak, the transition to green energy in energy sector is required. This transition helps to access to renewable energy and more sustainable modern energy services which improve the living conditions, promote economic growth and social development, protect the environment, and mitigate climate change. Moreover, access to modern energy services could help to improve the supply of basic services such as water supply, health, and education. According to Figure 3, as rural electrification expands, poverty levels would decrease. Hence, energy access and poverty alleviation are importantly correlated. Different studies emphasized that rural electrification supports the socio-economic welfare of the poor communities and it results in improvement of education, health, employment, and agriculture ${ }^{3-5}$.

Selecting the effective policies to develop the renewable energy and energy efficiency could significantly help to move towards green economy. A renewable energy source would provide a cost effective option for electrification of remote rural 
communities in Malaysia. An example of a successful renewable energy application for remote rural communities could be Bario Asal village, located in north east of Sarawak, who were dependent on diesel fuel to power their generators. Some of households in Bario are now using the electricity from a renewable source and some longhouses are connected to smaller capacity micro-hydro turbines as a viable energy option to supplement fossil fuels ${ }^{1}$. Application of green energy for poor communities not only has implications towards more efficient and cost effective use of energy, but also helps to focus on environmental and health hazards issues ${ }^{5}$.

\section{Impact of green economy on employment}

The economy sector in which many activities can happen within the green economy concept could be a driver of green jobs. The high potential sectors for green jobs are included energy supply (renewable energy), energy efficiency (building and construction), transportation, basic industry and recycling sectors, and agriculture ${ }^{6}$. For instance, promoting activities for agriculture and environment would create jobs such as eco-consultant in agriculture, eco-energy in the food industry, renewable energy and environmental consultants, and environmental educators. Another example is green building construction. For constructing green buildings, trades from design to implementation have potential to create green jobs such as green building architects, designers and engineers, and construction workers in green development ${ }^{7}$. Based on experts estimation, at least 52,000 jobs is expected to create from the construction, operation and maintenance of renewable energy plants in Malaysia by $2020^{\circ}$. Green jobs could improve environmental quality while reducing unemployment. Indeed, it has environmental, economic and social benefit.

In fact, new technologies and production processes for low-carbon production, improved energy and resource efficiency, and reduced pollution need forecasting of required skills. Malaysia in partnership with International Labour Organization (ILO) is forecasting future developments and preparing for technological and skills changes to come. Creation of green jobs in Malaysia from six sectors of energy, water and waste management, building, transportation, manufacturing, and ICT is expected to reach 451,704 jobs by 2025 . However, this would only be achieved with the right intervention programs such as providing incentives for green collar workers and developing the industry which would require workforce ${ }^{9}$. Skill training and education is also required, since most of employees are semiskilled workers.

\section{System Dynamics Approach}

In this study, the tool used to design a framework for building Malaysian green economy model is System Dynamics (SD) approach. SD is such a modelling methodology. This is a computer-aided approach for analyzing and solving complex problems with a focus on policy analysis and design. It is a methodology for studying and managing complex feedback systems. The way of studying a complex feedback system requires us to think the problem systematically. System thinking enables us to evaluate the transition problem more comprehensively by taking dynamic feedbacks into consideration. It helps to make everything in the system connect to everything else. SD model is developed by establishing a causal-loop relation between the components associated with the model in the form of a causal-loop diagram. Then a stock and flow diagram could be constructed and the dynamo equations could also be added to the model. In SD model, the simulations are essentially time-step simulations ${ }^{10-11}$.

From green economy for socio-economy development perspective, SD model recognizes sustainability as a whole systems concept concerned with poverty alleviation and job creation. The major contribution of the SD model is its systemic structure that includes endogenous links within and across the economic, social, and environmental sectors through a variety of feedback loops ${ }^{12}$. Most models focus on one or two sectors, however, make exogenous assumptions about other sectors which affect and are affected by the relevant sector ${ }^{13}$. SD applies endogenous formulations which develops consistency over time and across sectors. In fact, adjustments in the major drivers of the system analyzed are reflected in every parts of the model and analysis through feedback loops. Although detailed sectoral analysis is very important, it is not reasonable to show the whole set of relations and feedback loops that correctly indicate the functioning 
of the real world. It has to be considered in making the necessary transitions to greener economy and social structures ${ }^{14}$.

SD has helped many decision makers to think through how a policy may or may not work and what kind of result may come out. SD mostly discovers and represents the feedback process which indicates the dynamics of a system. Causal loop diagrams are graphic tools to represent the relationships between different elements of a system and their interactions. Drawing a causal loop diagram is a helpful process to get a better understanding of a system's feedback links. It is usually adequate to identify a system by means of its causal loop diagrams. But, sometimes a simulation model is built up and run to see how the basic reference modes of

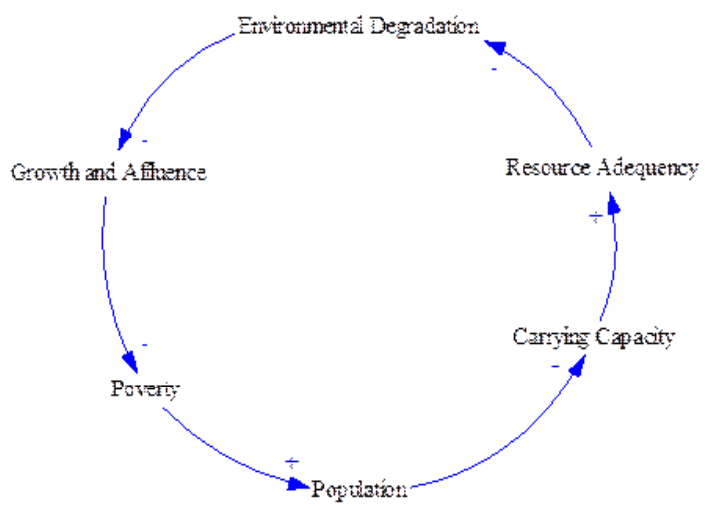

Fig. 1: Relationship between environmental degradation and poverty a system differ through time ${ }^{15}$. Simulation and policy analysis are not the intention of this paper and the causal loop diagrams are just designed for social, economic and environmental sectors as a framework for socio-economic development in Malaysia.

\section{Malaysian green economy framework for socio- economic development}

The first step to build the Malaysian green economy model is the identification of the need for developing the green economy and the existing features of green economy development in the country. A key feature of a green economy is that it attempts to provide various opportunities for economic development and poverty alleviation without eroding a country's natural assets. Hence, for shifting to a green economy, attempting to obtain

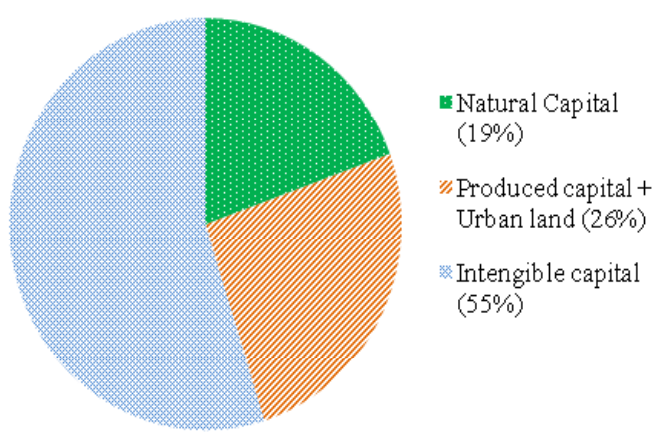

Fig. 2: The share of natural capital in the total wealth of Malaysia; (Source: Authors' calculations based on World Bank data, 2005)

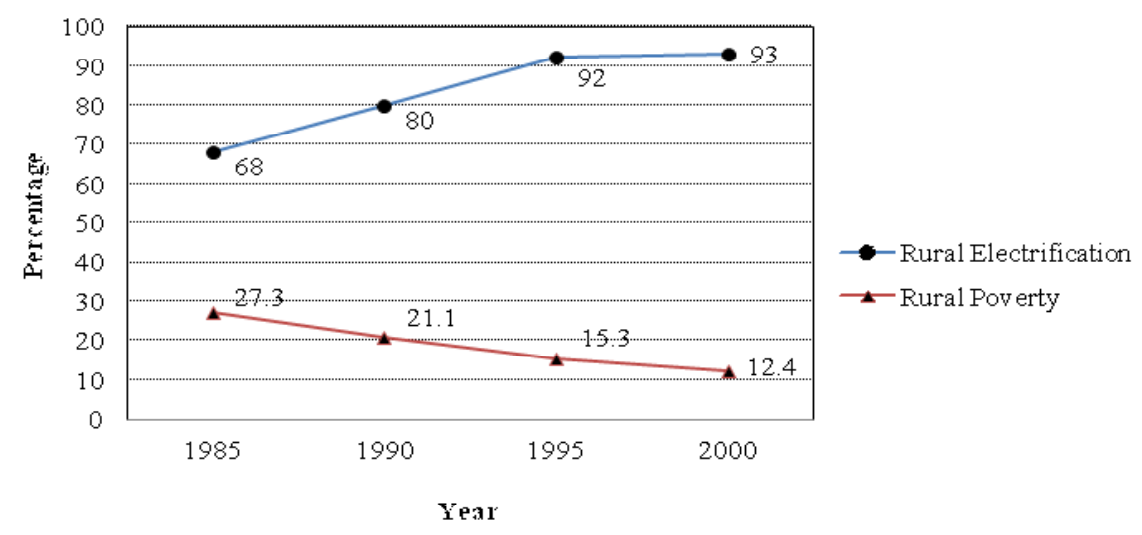

Fig. 3: Relationship between poverty alleviation and energy access in Malaysia (Source: Malaysian Department of Statistics, 2004) 
growth from environmental investment targeting poor communities should be the key component.

Figure 4 shows the interrelationships among components of the Malaysian green economy model for socio-economic development with application of green investment as a policy option.
Each arrow in this diagram shows the effect of one element on the other. If increasing one element causes another to increase, the effect is considered positive (+), or negative (-) in the opposite case. This is an economic growth model which is linked to social and environment. In this diagram, there are three main indicators, namely, socially inclusive (such as

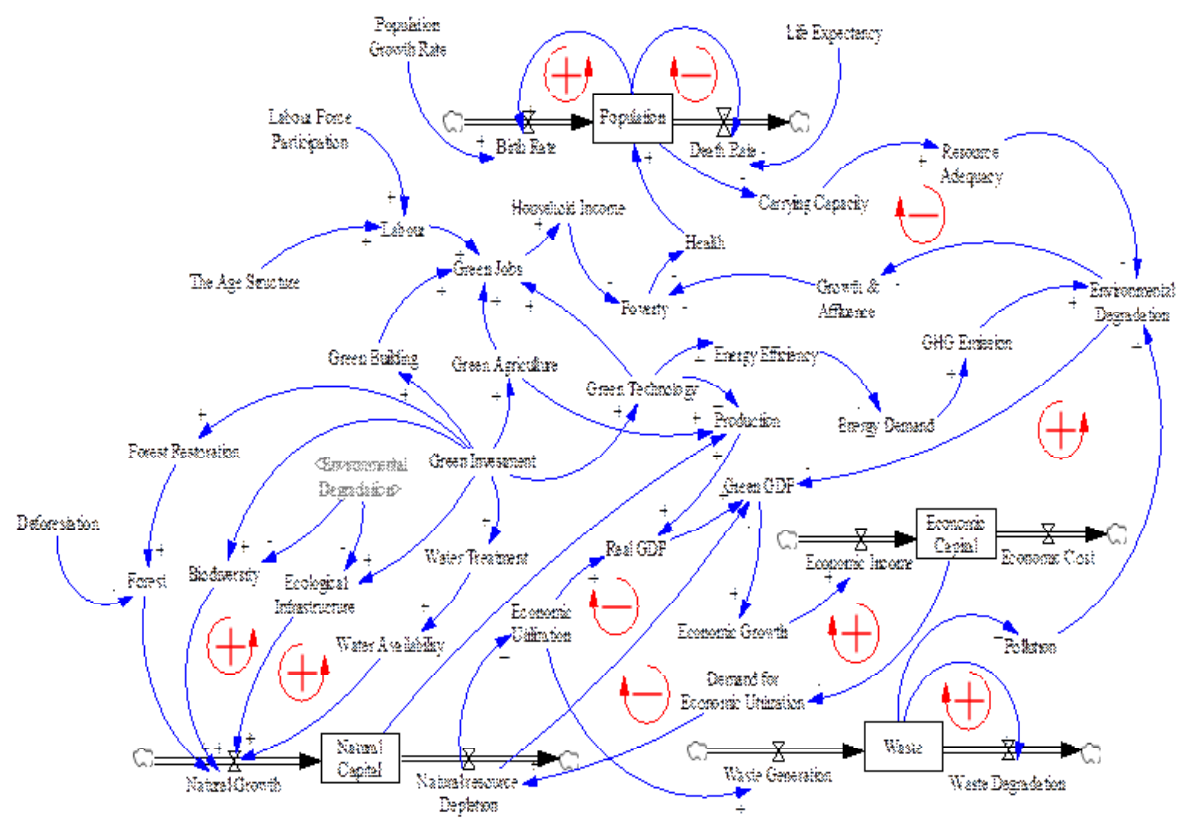

Fig. 4: The interrelationships among components of the green economy model

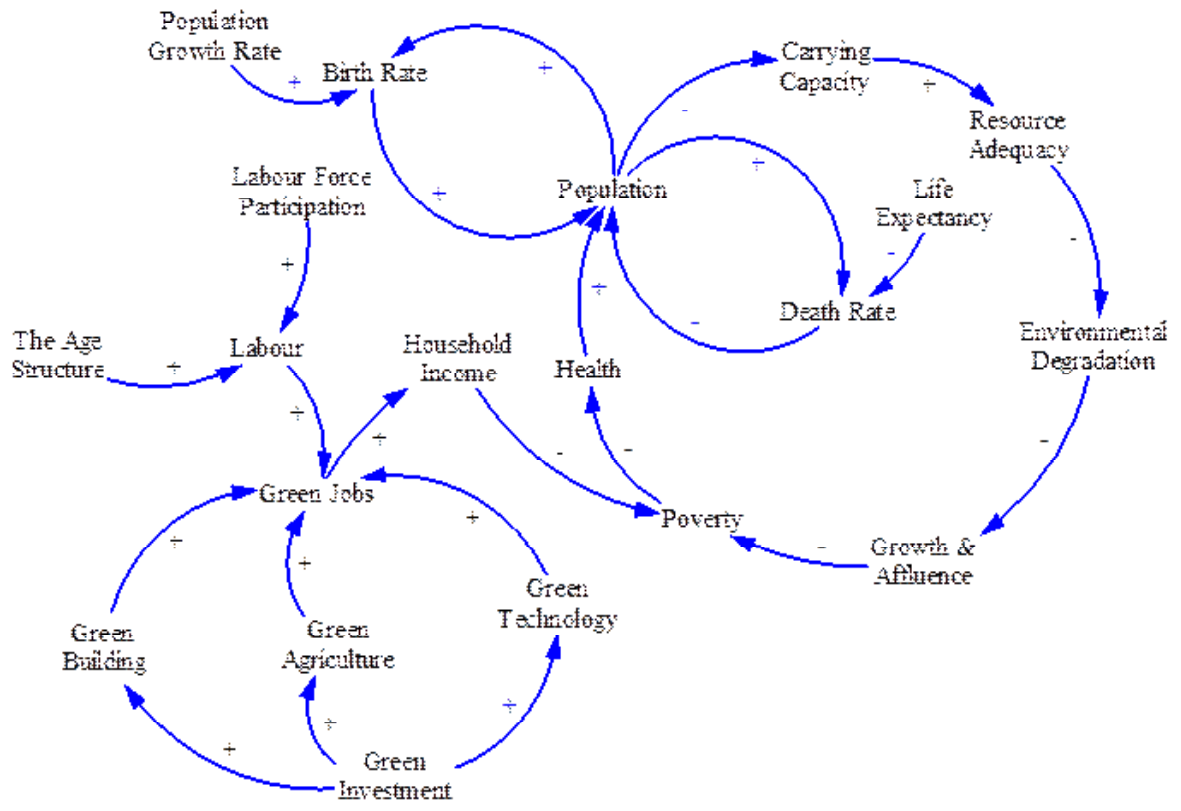

Fig. 5: Social structure 
poverty level and green jobs), low carbon energy (such as Green House Gas (GHG) emission and energy efficiency), and resource efficiency (such as natural capital and green GDP). This diagram could later be used to simulate and analyze the Malaysian green economy development under different policy scenarios.
This model is based on the green economy concept that believes the growth of economic capital which consumes the social and environment capital should return back by investing in social and environment capital. The investment in social capital would enhance awareness to conserve the environment. The environment could also support

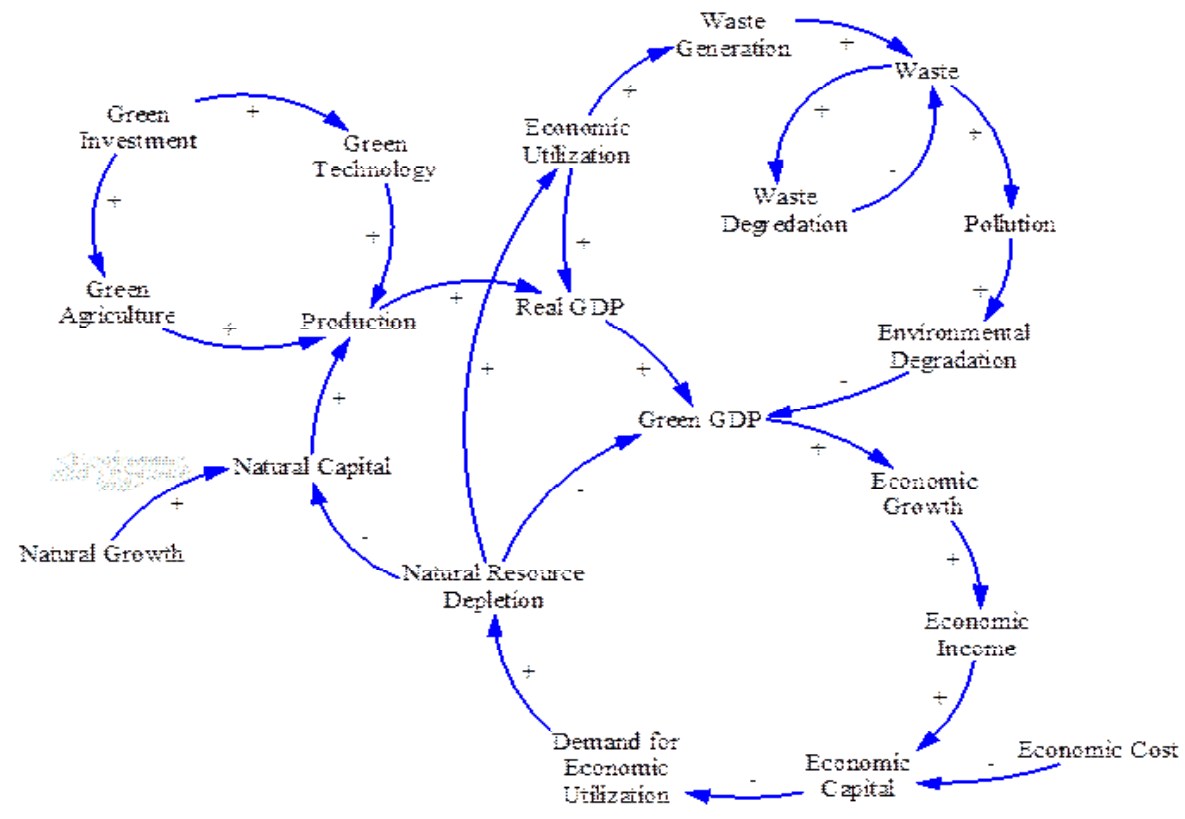

Fig. 6: Economic structure

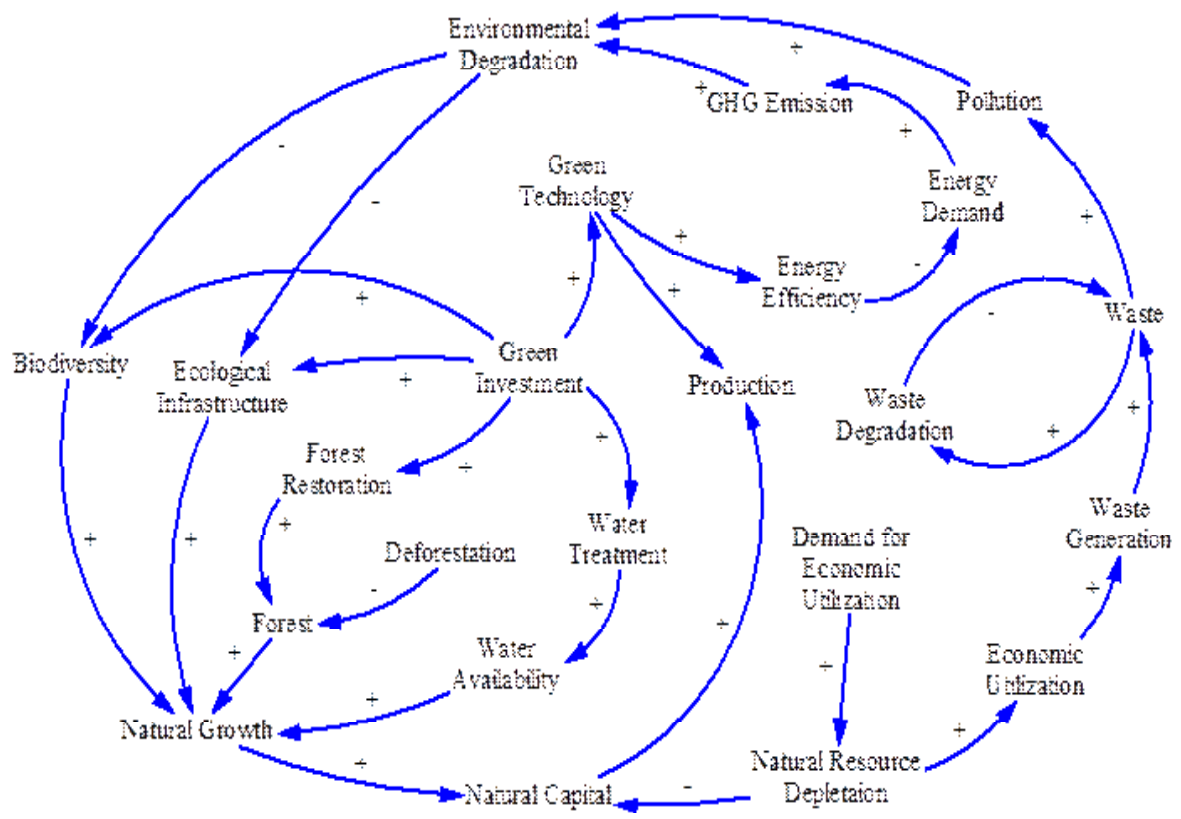

Fig. 7: Environmental Structure 
the growth of quality of life in the social capital. Based on UNEP ${ }^{13}$ report, the benefit flows from natural capital are received by the poor and vulnerable communities. It believes that a green economy could recognize the value of, and invests in, natural capital for sustainable development. It also helps to indicate the value of natural capital as a provider of human well being, supplier of livelihood of poor households, and a source of new jobs.

The causal loop diagram for social, economic and environmental structures are extracted from the main diagram and are presented separately in Figure 5-7, respectively. The social structure begins with population which depends on birth rate and death rate. Increasing population has negative impact on carrying capacity. It means that the number of people that an ecosystem can support would be less. Increasing population results in more demand for life services. Thus, the natural resources would be overused to support the population and the environment would also be degraded. When the natural resources become degraded, people who their livelihood mostly depends on natural resources could be easily pushed into poverty trap. On the other side, poverty could also cause environmental degradation through increasing population. Based on previous studies in Malaysia, lower income groups are experiencing faster rates of population increase ${ }^{16,17}$. In fact, poverty and low earnings result in poor health, nutrition, and maybe physical and mental development which lead to poor performance in school and work. It causes a lack of job prospects. Hence, more children would be needed, especially for people who are dependent on farming, to provide labour and security in old age. As a result of that population would increase and the cycle repeats. However, creating new jobs could significantly alleviate poverty through increasing household income. Green investment in some key economic sectors like agriculture and buildings could help to increase the employment rate.

The economic structure starts with economic capital which is accumulation of economic income and economic costs. There is a negative relationship between economic capital and demand for economic utilization. If economic capital decreases, demand for economic utilization and extraction of natural resources would increase.
This is one of the important linkages between economic and environmental structure. Economic utilization would enhance GDP of the country which would increase the economic growth and economic income of the country. Economic growth basically refers to the real growth in Gross Domestic Product (GDP). However, in this diagram, the green GDP term is used. Because the conventional or real GDP is computed as a sum of all final goods and services at market prices and it ignores externalities, especially environmental ones. It does not measure some important things in our economic well being such as clean air and water ${ }^{18}$. In fact, real GDP does not measure the sustainability of growth. This deficiency could be prevailed by measuring the green GDP which considers the natural capital depreciation and environmental degradation as well. On the other side, more economic utilization may generate more waste and more pollution which will cause environmental damages. This is another linkage between economic and environmental structure. Environmental degradation results in loss of biodiversity and ecological infrastructure which negatively affect on natural capital.

Nature plays an important role in human well-being in terms of food security, health, and job creation. Forests as natural capital are the part of ecological infrastructure which also supports human well-being. Increasing forest restoration and reducing deforestation may support rural livelihoods and make a good economy sense. Forest restoration could increase the value added in the forest industry, enhance employment in this sector, increase carbon sink, and reduce the GHG emission. Investments in forest, biodiversity and ecological infrastructure could maintain, restore and increase ecological goods and services, and therefore would add to the value of natural capital. Water as a basic ecosystem services could also be green by investments in infrastructure and water policy reform to ensure that enough quality and quantity of water are provided for both people and ecosystems. Investing in natural capital may help to increase the productivity, and therefore enhance the GDP and economic growth of the country. On the other hand, investment in green technology may improve energy efficiency and reduce energy consumption. It leads to reduction in GHG emission and positively affect on environment. 
In figure 4 , all loops are controlling the structure of the system and sustain it at a balanced level. Hence, it would be a sustainable system when the loops function correctly. Nevertheless, changes in exogenous variables like green investment may result in effective changes to loops.

\section{Key Green Economy Interventions}

Malaysia's approach to achieve green economy follow a conventional economic framing such as UNEP and Organisation for Economic Cooperation and Development (OECD), by focusing on economic parameters such as regulation, investments, incentives, tax, and pricing ${ }^{1}$. UNEP ${ }^{13}$ defined the most important areas for green policy making. These areas are included addressing environmental externalities and existing market failures, limiting government spending in areas that deplete natural capital, promoting investment in areas that simulate a green economy, fostering infant green industries, establishing a sound regulatory framework to channel investments into environmentally and socially valuable activities, and strengthening international frameworks that regulate economic activity.

Malaysia is blessed with a wealth of natural resources. Government as a policy maker has to ensure that the environmental assets and ecological resources are managed sustainably to make sure that the present development would not threaten future generations. Based on Tenth Malaysian Plan, government planned some initiatives to promote sustainability measures in the country. For instance, they introduced Feed-in-tariff to help finance renewable energy investment. The energy efficiency is one of the important elements in Malaysian energy policy framework. Investments in energy efficiency and renewable energy may help to improve the efficiency and productivity of environmentally friendly technologies. It also helps to reduce the energy intensity and adverse environmental impacts. Designing the energy efficient buildings plays an important role in mitigating climate change and shifting to a global green economy.

Government provided fiscal incentives and funding for green technology investments ${ }^{19}$. Development of green technology could be an effective strategy for Malaysian socio-economic development due to its environmental, social and economic impacts which are reduction of carbon emission, increasing high income jobs, and increasing GDP of the country, respectively. The Malaysian national green technology policy (NGTP) which introduced in July 2009 is a driver to accelerate the national economy and promote sustainable development. It is launched by Prime Minister of Malaysia, with objectives of minimizing growth of energy consumption while improving economic development, facilitating the growth of the green technology industry and increasing its contribution to the national economy, enhancing national ability and capacity for innovation in green technology development and increase Malaysia's competitiveness in the global arena, ensuring sustainable development and conserve the environment for future generations, and finally, increasing public awareness on green technology and encourage its widespread use. The energy efficiency and renewable energy is also promoted and supported under this policy ${ }^{20}$. Since natural capital is instrumental in supporting the economic sectors and social well-being, investing in the maintenance, restoration and enhancement of natural capital may significantly promote the economic growth of the country and deliver income benefits for the society. The Tenth Malaysian Plan recognized that proper valuation of environmental and ecological resources is important to ensure these resources are used sustainably ${ }^{19}$. Government is working on that by focusing on the link between the conservation of ecosystems and business operations.

To achieve a successful transition, government has to enable conditions that would create rights and initiatives related to green economy activities, remove barriers to green investments, and regulate the most damaging forms of unsustainable behaviour. Furthermore, education and training for new green employees and more sustainable future should be the main focus.

\section{CONCLUSIONS}

Economy growth is mostly accompanied with environmental degradation. This degradation generates unsustainability and poverty trap. Hence, transition to the green economy which is more socially equitable and environmentally reasonable 
is needed. Green economy could have different impacts on human well-being such as improved access to clean energy and water, improved nutrition, increased employment, and reduced poverty. A key feature of a green economy is that it attempts to provide various opportunities for economic development and poverty alleviation without eroding a country's natural assets. Thus, for shifting to a green economy, attempting to obtain growth from environmental investment targeting poor communities should be the key component. This paper proposes that for the inclusive green growth for socio-economic development shifting in investment towards green activities should be considered as the main policy instrument. Green investment would help to improve the environment which this environmental improvement is also consistent with GDP growth and wealth creation.

\section{ACKNOWLEDGEMENT}

This work was prepared under research projects ERGS/1/2013/SS07/UKM/01/1 and FRGS/1/2012/SS07/UKM/01/3 led by Professor Chamhuri Siwar and DPP/2013/073 led by Associate Professor Dr. Sarah Aziz Abdul Ghani Aziz at Universiti Kebangsaan Malaysia (UKM).

\section{REFERENCES}

1. Hezri, A. A. and Ghazali, R. A., Fair Green Economy? Studies of Agriculture, Energy and Waste Initiatives in Malaysia. Occasional Paper Two, Social Dimensions of Green Economy and Sustainable Development (2011). http://www.fes-globalization.org/ geneva.

2. UNEP., Green economy, briefing paper: poverty reduction. http://www.unep.ch/etb/ publications (2012).

3. Cook, P., Rural Electrification and Rural Development. In Rural Electrification Through Decentralised Off-grid Systems in Developing Countries (pp. 13-38). London: Springer (2013).

4. Reiche, K., Covarrubias, A. and Martinot, E., Fuel, 1(1.2): 1-4 (2000).

5. UNDP., Energy and Poverty in Malaysia: Challenges and the Way Forward. UNDP, Bangkok (2007).

http://www.snap-undp.org/elibrary/Publications/ EnergyAndPovertyMalaysia.pdf.

6. Szovics, P., Tessaring, M., Walmsley, C. and McGrath, J., 10. Future skill needs for the green economy. Future skill needs for the green economy, 90 (2009). http://www. forschungsnetzwerk.at.

7. Chua, S. C. and Oh, T. H., Renew. Sust. Energ. Rev. 15(6): 2850-2861 (2011).

8. Ang, E., Renewable energy a growth sector for Malaysia. 28 August. The Star (2010). http://www.thestar.com.my.

9. Ismail, A. Z., Malaysian green building confederation. Empowering green markets forum. 9 October, Kuala Lumpur (2013). http:// www.mgbc.org.my.

10. Forrester, J.W., Building a System Dynamics Model. Prepared for the MIT System Dynamic in education project under the supervision of Dr. Jay W. Forrester, Massachuset Institut of Technology (1997).

11. Sterman, J. D., Business dynamics: systems thinking and modelling for a complex world. McGraw-Hill Higher Education (2000).

12. Roberts, N., Andersen, D. F., Deal, R. M., Garet, M. S. and Shaffer, W. A., Introduction to computer simulation: the system dynamics approach. Addison-Wesley Publishing Company (1983).

13. UNEP., Towards a Green Economy: Pathways to Sustainable Development and Poverty eradication - A synthesis for policy makers (2011). http://www.unep.org/greeneconomy.

14. Van Paddenburg, A., Bassi, A., Buter, E., Cosslett, C., and Dean, A., Heart of Borneo: Investing in Nature for a Green Economy. WWF Heart of Borneo Global Initiative, Jakarta (2012).

15. Hjorth, P. and Bagheri, A., Futures, 38(1): 74-92 (2006).

16. Hashim, S. M. (Ed.)., Income inequality and poverty in Malaysia. Rowman \& Littlefield. 
pp. 243 (1998).

17. Putra, I. S., Poverty, Population Growth, and Human Capital Development in Kedah Darulaman. Doctoral dissertation, Universiti Utara Malaysia (2012).

18. Van den Bergh, J. C. J. M., Abolishing GDP. Tinbergen Institute Discussion, 19(3) (2007). http://papers.tinbergen.nl/07019.pdf.
19. Tenth Malaysia Plan 2011-2015., The Economic Planning Unit, Prime Minister Department, Putrajaya (2010).

20. NGTP., National green technology launched today. Press, NST online, 24 July (2009). http:// envdevmalaysia.wordpress.com/2009/07/24/ national-green-technology-policy-launched. 